\title{
Seasonal Trends in the Condition of Nesting Females of a Solitary Bee: Wing Wear, Lipid Content, and Oocyte Size
}

Kevin M. O'Neill, Casey M. Delphia, Theresa L. Pitts-Singer

During the nesting season, adult females of the solitary bee Megachile rotundata ( $F$.) face considerable physical and energy demands that could include increasing wear and tear on their bodies and decreasing lipid reserves. Consequently, their reproductive performance may be affected not only by extrinsic factors (e.g. weather and floral resource availability), but intrinsic changes in their own bodies. Because of the potential fitness effects of seasonal changes in body condition, our objectives were to determine how wing wear, lipid reserves, and oocyte sizes vary during nesting seasons, beginning when females emerge as adults. As nesting progressed, females in two populations experienced a steady increase in wing wear, which is known to reduce foraging efficiency and increase risk of mortality in other bees. Soon after emergence, females exhibited sharp declines in lipid content which remained low for the remainder of the season. Newly-emerged females ingested pollen, an activity known to be correlated with the initiation egg maturation in this species. Additionally, the early summer drop in lipid stores was correlated with an increase in the size of the oocytes carried. However, by $\sim 6$ weeks after emergence, oocytes began to decrease in length and volume, perhaps due to nutrient deficiencies related to loss of stored lipids. Our results suggest management of $M$. rotundata should include rearing bees at temperatures that maximize stored lipid reserves in adults and timing bee release so that significant pollen resources are available for both adults and offspring. 
2 Kevin M. O'Neill ${ }^{1}$, Casey M. Delphia ${ }^{1,2}$, and Theresa L. Pitts-Singer ${ }^{3}$

3

4

$5{ }^{1}$ Department of Land Resources and Environmental Sciences, Montana State University, Bozeman,

6 MT, USA; ${ }^{2}$ present address: Department of Ecology, Montana State University, Bozeman, MT, USA; ${ }^{3}$

7 USDA-ARS Pollinating Insects Research Unit, Utah State University, Logan, UT, USA

8

9

10 Corresponding Author: Kevin M. O'Neill

11 Department of Land Resources and Environmental Sciences

12 Montana State University, MT, USA

13 Office: 18 Marsh Labs

14 Phone: (406) 994-2333

15 Email: koneill@montana.edu

16

17 Subject Areas Ecology, Entomology

18 Keywords Megachilidae, Megachile rotundata, egg size, reproduction, pollinators

19 


\section{INTRODUCTION}

22 The nesting season of the leafcutting bee Megachile rotundata (F.) (Hymenoptera: Megachilidae) is a

23 period of intense physical activity, each female acting on her own to modify and provision a nest cavity

24 (Pitts-Singer \& Cane, 2011). During this time, females experience considerable energy demands and

25 physical stresses from the large number of flights taken to collect pollen, nectar, and nesting materials.

26 Soon after emerging as adults, females also begin to produce relatively large eggs (Richards, 1994), as

27 is the case in other solitary, nest-provisioning Hymenoptera (Iwata, 1955, 1960; K.M. O'Neill, 2001).

28 Thus, we expect females to experience seasonal declines in both physical condition and the lipid

29 reserves they carry over from earlier developmental stages (K.M. O'Neill et al., 2011).

30 Questions concerning reproductive performance of adult $M$. rotundata are relevant to their

31 value as pollinators of alfalfa grown for seed production (Pitts-Singer \& Cane, 2011). Following

32 removal of bee cells from winter storage, $M$. rotundata are reared from prepupae to adults over 3-4

33 weeks before being released into field nest shelters containing thousands of potential nest sites.

34 Rearing is timed so that cells are placed in fields as the alfalfa starts blooming and as adult females

35 begin to emerge. Unlike honey bees and bumble bees, which produce new batches of foragers

36 throughout the growing season, adults of solitary bees like $M$. rotundata emerge more synchronously.

37 Even if a partial second generation appears later in the summer, it is the adult females from the

38 overwintering generation that are present over the 4-6 weeks when most of the alfalfa flowers are

39 pollinated (Strickler \& Freitas, 1999; Bosch \& Kemp, 2005). Thus, it is of interest to determine

40 whether the condition of adult females changes seasonally, in ways that could affect the consistency of

41 their performance as pollinators and as parents of the generation of bees that will be released during the

42 following year's growing season.

43 The effect of management strategies on the survival and development of the immature stages of

44 M. rotundata has been studied during the summer nesting season (Pitts-Singer \& James, 2008; Pitts- 
45 Singer, 2013b), during fall and winter storage of bee cells (Richards, Whitfield \& Schaalje, 1987; Pitts-

46 Singer \& James, 2005, 2009), and while bees are being reared prior to release into fields (Yocum et al.,

47 2010; K.M. O'Neill et al., 2011). However, few studies have examined factors that could change

48 seasonally and affect the fitness of adult females while they are nesting. First, wings of female solitary

49 bees accumulate wear (Mueller \& Wolf-Mueller, 1993; Wuellner, 1999; López-Uribe, Oi \& Del Lama,

50 2008) that is known to affect the foraging success and reproductive performance of bees (Cartar, 1992;

51 Higginson \& Barnard, 2004; Foster \& Cartar, 2010; Rehan \& Richards, 2010). Second, lipid stores

52 within fat bodies may decline, potentially influencing egg production, as they do in other insects

53 (Arrese \& Soulages, 2010). The importance of lipid stores is suggested by the fact that $\sim 20 \%$ of fresh

54 weight of diapausing prepupae of M. rotundata consists of lipids. That value is greater than in most

55 other insects, including honey bees (Buckner, Kemp \& Bosch, 2004). Although much of the lipid in

56 fat bodies may be metabolized during the pupal-to-adult transition, some females emerge with lipids

57 comprising $>25 \%$ of their dry weight (K.M. O'Neill et al., 2011). A question that remains, however, is

58 how rapidly these stores are depleted in adults. Third, the decline in lipid stores, whenever it occurs,

59 may also be correlated with a reduction in the size of developing oocytes, which peak in volume about

60 five weeks after emergence (Richards, 1994). Of these three female qualities, only temporal changes in

61 ovary condition have been quantified (Richards, 1994), and questions remain regarding changes in

62 oocyte size.

Given the potential fitness effects of seasonal changes in female body condition, the objectives

64

65

66

67

68 of this study were to determine how wing wear, body lipid reserves, and oocyte sizes vary across

nesting seasons, beginning at the time when females appear as adults. Our study was conducted during two field seasons at one site in Montana (MT) and one season at a site in Utah (UT), where we collected bees weekly or bi-weekly following their release into alfalfa fields. We also recorded qualitative assessments of the pollen carried in the guts of females, pollen being the only significant 
source of protein in adult female diets. We discuss the implications of the results for reproductive strategies of solitary bees and for management of this widely-used pollinator.

\section{MATERIALS AND METHODS}

\section{Study sites and collection methods}

We collected bees at two sites: 1) 3 km west of Laurel, MT (45³9’10.99” N, 10849’39.36”W)

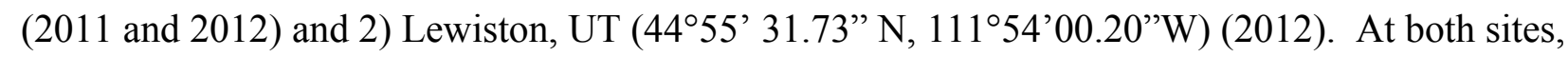
cooperating growers released $M$. rotundata into nest shelters within commercial seed alfalfa fields. Each year, our first sample was taken within 1-2 days of the release, by using sweep nets to collect females entering and leaving nest entrances. Most, if not all, females were recently eclosed and in the early stages of nesting activities. We returned to the sites weekly (or bi-weekly for most samples in 2011 in MT) to obtain further samples in the same manner. We continued sampling until 1) populations declined and few females remained active or 2) the growers removed the nests from fields (see below). All samples were immediately placed in a cooler with ice and frozen later the same day to reduce the likelihood of females sustaining further wing wear or metabolizing lipids after capture. In 2012 in MT, a second set of sweep samples was collected at nest shelters on five dates and used for analysis of ovary condition and relative oocyte size. Females in these samples were immediately placed in Kahle's solution upon return to the lab. We originally planned to sample through the time when numbers of females declined later in the summer, but the grower at the MT site removed bee shelters from the field earlier than usual because of the condition of the alfalfa.

\section{Quantification of wing wear}

To quantify wing-wear, we used the index of wing wear (WW) developed for bees by Mueller \& WolfMueller (1993). For each bee, we used a stereomicroscope to record the number of nicks on the apical 
93 edge of each forewing, the relative size of the nicks, and the proportion of intact margin to determine

94 WW as follows: $0=$ a completely intact apical margin; $1=1-2$ nicks on the apical margin; $2=3-10$

95 nicks on the margin; $3=$ some wing margin intact, though heavily serrated, with $>10$ nicks; $4=$

96 completely serrated with no apical wing margin intact, but with excisions less than half the width of the

97 distal submarginal cell; $5=$ wing as described in 4 , but with excisions more than half, but less than the

98 entire width of the distal submarginal cell; and $6=$ wing as described in 4 , but with excisions greater

99 than the width of the distal submarginal cell (Mueller \& Wolf-Mueller, 1993). Like Mueller \& Wolf-

100 Mueller, we ignored large excisions present on one wing only, because they seemed not to be

101 indicative of gradual wing wear. We evaluated the margins of the left and right forewing of each bee

102 and scored them separately according to the WW classes described above, and then averaged the scores

103 from the forewings to derive a single WW score for each bee. We tested the hypothesis that WW

104 varied with date of collection using Kruskal-Wallis Tests, followed by Dunn's test for multiple

105 comparisons (Zar, 1999; SigmaPlot v. 11.0; Systat Softfware, Inc.).

106

\section{Quantification of body lipid content}

108 We quantified body lipid content using the same bees for which we measured WW, following a

109 method used previously for solitary bees (Richards \& Packer, 1994; K.M. O'Neill et al., 2011) and

110 wasps (Strohm, 2000). Bees were removed from the freezer and placed within separate glass vials in a

$11155^{\circ} \mathrm{C}$ drying oven. After four days, a subset of 15 bees was removed and their dry masses were

112 individually determined to the nearest $0.01 \mathrm{mg}$ on a Sartorius TE64 balance (Goettingen, Germany).

113 After returning them to the oven, we reweighed the same 15 bees $24 \mathrm{~h}$ later to determine if their body

114 masses had stabilized; if not, they were again returned to the oven and the procedure was repeated

115 daily until stable masses were obtained. At that time, all bees were weighed. To extract lipids from

116 dried bees, we added $10 \mathrm{ml}$ of petroleum ether to each vial as soon as the bees were removed from the 
117 oven and capped it. After 10 days, we decanted the ether and air-dried the vials containing the bees for

118 one hour under a laboratory hood. The vials were then placed back into the oven until the masses

119 again stabilized ( $72 \mathrm{~h}$ ) before a post-extraction body mass was obtained. We subtracted post-

120 extraction dry mass from the pre-extraction dry mass to estimate of the amount of lipid extracted. The

121 result was then divided by the pre-extraction dry mass to obtain an estimate of the proportion of dry

122 mass comprised of lipids $\left(\mathrm{P}_{\mathrm{L}}\right)$ for each bee. Each year, all bees collected during the summer were

123 subjected to lipid analysis at the same time to avoid any variation that might be introduced by minor

124 variations in handling technique or conditions in the lab.

125 Using one-way analyses of variance (ANOVA; SigmaPlot v. 11.0, Systat Softfware, Inc.), we

126 tested the hypothesis that the $\mathrm{P}_{\mathrm{L}}$ varied with 1) collection date and 2) WW. Before analysis, $\mathrm{P}_{\mathrm{L}}$ values

127 were transformed as the arcsine of the square root of $\mathrm{P}_{\mathrm{L}}$ (Zar, 1999). Pairwise comparisons were

128 conducted using Student-Newman-Keuls (SNK) tests. We compared proportions of females with $\mathrm{P}_{\mathrm{L}}$

129 values $\geq 0.10$ and $\leq 0.05$, contrasting the first collection date each year with all other collection dates

130 combined using Fisher Exact Tests.

\section{Quantification of ovary condition and oocyte size}

133 The females stored in Kahle's solution were dissected under ethanol so we could measure oocytes using

134 a stereomicroscope equipped with an ocular micrometer. We dissected from 26-32 females collected

135 on each of five dates in 2012 ( $\operatorname{total} N=145$ ). To reduce the likelihood of having second generation

136 females included in the 3 August sample, we dissected only bees with $\mathrm{WW} \geq 1$ for that date. For each

137 female, we recorded: 1) head width (HW; to the nearest $0.5 \mathrm{~mm}$ ), as an indicator of overall body size,

138 2) WW as described above, but for the right forewing only (the latter was deemed sufficient because

139 we had determined in the other wing wear analysis that WW values for the two wings on each female

140 differed by $\leq 1$ in $>97 \%$ of females), 3) length ( $\mathrm{L}$ ) and diameter ( $\mathrm{D}$, at the midpoint of its long axis) of 
141 each of the three longest oocytes (if the oocyte was somewhat flattened by being pressed against the 142 inner wall of the exoskeleton, we recorded the midpoint value between the greatest and smallest 143 width), and 4) whether the largest oocyte was allantoid (i.e., sausage-shaped, or a cylinder with 144 hemispherical ends), as is typical of mature oocytes (Iwata, 1955). For allantoid basal oocytes (i.e., 145 those next in line for oviposition and the largest oocyte in each female), we estimated their volume (V 146 in $\left.\mathrm{mm}^{3}\right)$ as $\mathrm{V}=(4 / 3)\left(\pi \mathrm{r}^{3}\right)+\left(\pi \mathrm{r}^{2}\right)(\mathrm{L}-2 \mathrm{r})$, where $\mathrm{r}=\mathrm{D} / 2$. Other oocytes approximated a prolate spheroid 147 in shape, so we estimated their volume as $\mathrm{V}=(4 / 3)(\pi)\left(\mathrm{r}^{2}\right)(\mathrm{L} / 2)$.

148 The mean head widths of females dissected did not differ significantly among the five sample 149 dates (one-way ANOVA: $F=1.61 ; \mathrm{df}=4,140 ; P=0.17$ ). Nevertheless, to test the hypothesis that 150 oocyte size variables changed across the nesting season independent of body size, we standardized 151 oocyte variables across head widths by calculating the ratios of four oocyte size variables to HW. The 152 four variables were the maximum length $\left(\mathrm{L}_{\text {basal }}\right)$ and volume $\left(\mathrm{V}_{\text {basal }}\right)$ of the basal oocyte and the 153 summed maximum lengths $\left(\mathrm{L}_{\text {total }}\right)$ and summed volumes $\left(\mathrm{V}_{\text {total }}\right)$ of the three measured oocytes. We 154 then used Kruskal-Wallis Tests to compare ratios among dates (with Dunn's Test for comparisons 155 among pairs of dates; $\alpha=0.05$ ).

To test the hypothesis that oocyte variables differed among females with different degrees of 157 wing wear, we began by regressing $\mathrm{L}_{\text {basal }}, \mathrm{L}_{\text {total }}, \mathrm{V}_{\text {basal }}$, and $\mathrm{V}_{\text {total }}$ on $\mathrm{HW}$. We used the resulting linear 158 regression equations to determine which females had negative residuals (i.e., smaller than expected 159 oocytes) and positive residuals relative to predicted values from the regressions. We used Mann160 Whitney Tests to determine if females with negative residuals had WW values different from those 161 with positive residuals. We also correlated WW with the four oocyte variables using Spearman Rank 162 Correlation tests. 


\section{Observations of pollen loads in guts}

167 For each female dissected, we recorded whether their crops and midguts were mostly full of pollen, as

168 opposed to having a few pollen grains. To determine whether most of the pollen was likely from

169 alfalfa plants, we dissected ten randomly chosen females each from the 22 June and 3 August samples;

170 these females were not included in the oocyte analyses. We chose those two days because our previous

171 research showed that females collect mainly alfalfa pollen early in the nesting season, but often add

172 significant amounts of pollen from other plant species later in the nesting season (R.P. O’Neill \& K.M.

173 O’Neill, 2010). Thus, we expected any changes that might occur in pollen loads in guts would be

174 detected by examining females from the first and last collection dates of the year. We used a

175 micropipette to remove a sample of pollen from their guts and examined the pollen using 10x and 40x

176 power under a compound microscope. One hundred pollen grains counted along a transect on the slide

177 were scored as being either alfalfa or non-alfalfa pollen based on comparison to reference collections

178 that we made for previous studies (K.M. O'Neill et al. 2004; R.P. O’Neill \& K.M. O’Neill, 2010).

\section{RESULTS}

\section{Seasonal trends in wing wear}

182 Tattering of the forewings of $M$. rotundata occurs mainly along the apical margins where they are

183 unsupported by bordering wing veins beyond the distal terminus of the costal vein. Wing wear varied

184 significantly over the course of each nesting season at both locales (Fig. 1; Kruskal-Wallis Tests, $P<$

1850.001 for each of the three sets of samples), but there was considerable variation among females

186 collected after the first sampling dates. After a steady rise in mean WW early in the nesting season, it

187 reached a plateau in both years at the MT site and declined at the UT site. Most bees collected on the 
188 first date each year exhibited WW values of $\leq 0.5,96 \%$ for MT in $2011,97 \%$ for MT in 2012 , and $77 \%$ 189 for UT in 2012.

190 In the two sets of MT samples, mean WW rose during the first 3-4 weeks following release.

191 During the last three sampling dates combined, WW values were $\geq 4.0$ in $43 \%$ of females in 2011 and

$19263 \%$ in 2012. For the UT bees, mean WW increased from $<0.5$ on the first collection date to 3.7 about

193 three weeks following bee release, with $57 \%$ of WW values at that time being $\geq 4.0$. However, mean

194 WW then declined to 2.1 on 18 July $(\mathrm{JD}=200)$, with $30 \%$ of the values being $\leq 0.5$ and just $12 \%$ being

$195 \geq 4.0$; as discussed later, this likely occurred because of an influx of a second generation of bees into the

196 population. The following week $(\mathrm{JD}=207)$, the mean rose to its seasonal peak of 4.5 , with all values

197 exceeding 2.5 and $83 \%$ being $\geq 4.0$. During the last three dates, the mean again declined to $\sim 1.5-2.5$.

198 Wing wear was generally symmetrical between the left and right forewings. Among the 748

199 females examined, scores for the two wings were identical in $61.5 \%$ of females and differed by just one 200 in another $35.7 \%$ of females. Wing wear scores never differed by more than two in any one female.

202 Seasonal trends in lipid content

203 The lipid content of females varied significantly over the course of the nesting season in all three sets

204 of samples (Table 1, Fig. 2, left). Body lipids declined after field release, the initial decrease in mean

$205 \mathrm{P}_{\mathrm{L}}$ ranging from $30-39 \%$ in the three sets of samples. The $\mathrm{P}_{\mathrm{L}}$ values then remained relatively constant

206 for the remainder of each summer, with the exception of the brief increase in the 18 July (JD $=200)$

207 sample in Utah in 2012 (i.e., the same date on which WW values declined). The proportions of

208 females with $\mathrm{P}_{\mathrm{L}} \geq 0.10$ on the first collection date was greater than the proportions for all other dates

209 combined (Table 2). Conversely, the proportion of females on the first collection date with $\mathrm{P}_{\mathrm{L}} \leq 0.05$

210 was smaller than the proportions on all other dates combined. 
211 Given the great variation in female WW values on most dates, it seems clear that date of

212 collection is not an accurate estimate of females' physiological ages (i.e., the cumulative amount of

213 physiological/behavioral activity in their adult lives that is reflected in the degree of wing wear); this is

214 especially the case later in the season when some second generation females emerge. In each sample

$215 \mathrm{P}_{\mathrm{L}}$, varied significantly across WW categories (Kruskal-Wallis Tests, $P<0.001$ for each site/date

216 combination; Fig. 2, right), with the decline in $\mathrm{P}_{\mathrm{L}}$ across WW classes, being more gradual than that

217 observed across dates. Females with WW values $\geq 4.5$ had mean $\mathrm{P}_{\mathrm{L}}$ values about $35 \%$ (MT 2011) to

$21848 \%$ (MT and UT 2012) that of females with WW values of zero (Table 1).

\section{Seasonal trends in oocyte size}

221 In dissected females, the crop occupied most of the anterior half of the metasoma. The ovaries shared

222 the limited space in the posterior half with other organs. Particularly when the crop was inflated with

223 nectar/pollen, the interior cavity of the metasoma was often so crowded that larger oocytes were

224 pressed against the inner surface of the integument and sometimes had indentations conforming to

225 boundaries between metasomal segments. As oocytes matured and moved towards the position of

226 being basal oocytes, they typically changed from being prolate spheroid-shaped to allantoid. Just $50 \%$

227 of the 30 females dissected from the 22 June sample had allantoid basal oocytes. Over the next three

228 dates combined, $99 \%(N=85)$ of females had at least one allantoid oocyte, but the percentage declined

229 to $73 \%$ by 3 August $(N=30)$.

230 Our primary objective was to determine if oocyte size variables ( $\mathrm{L}_{\text {basal }}, \mathrm{L}_{\text {total }}, \mathrm{V}_{\text {basal }}$, and $\left.\mathrm{V}_{\text {total }}\right)$

231 changed as the nesting season progressed, but analysis is complicated by the correlation of body size

232 with oocyte size (K.M. O'Neill, Delphia \& R.P. O’Neill, 2014). To remove the confounding effect of

233 body size, we calculated ratios of each of the four oocyte variables to head width. All four ratios

234 varied significantly across the five sampling dates (Fig. 3; Kruskal-Wallis Tests, $P<0.001$ for each of 
235 the four variables), primarily because of the low ratios for 22 June. However, the $\mathrm{L}_{\text {total }} / \mathrm{HW}$ and

$236 \mathrm{~V}_{\text {basal }} / \mathrm{HW}$ ratios rose at the beginning of the nesting season, but then declined significantly by early

237 August.

238 To test the hypothesis that wing wear was correlated with oocyte size (independent of date of

239 collection and head width), we determined which females collected after 22 June had smaller- or

240 larger-than expected values for oocytes-size variables based on the regressions of those variables on

241 HW. Females with positive residuals (larger than expected oocyte sizes) had significantly lower WW

242 values than those with negative residuals for $\mathrm{L}_{\text {basal }}$ (Mann-Whitney Test, $\left.P<0.01\right), \mathrm{V}_{\text {basal }}(P<0.01)$,

243 and $\mathrm{V}_{\text {total }}(P<0.001)$, but not $\mathrm{L}_{\text {total }}(P=0.68)$ (Fig. 4). These results are reflected in the overall

244 correlations between the oocyte variables and WW which were significant and negative for $\mathrm{L}_{\text {basal }}$

245 (Spearman Correlation, $r=-0.22, P<0.05), \mathrm{V}_{\text {basal }}(r=-0.27, P<0.01)$, and $\mathrm{V}_{\text {total }}(r=-0.27, P<0.01)$,

246 but not $\mathrm{L}_{\text {total }}(r=-0.14, P=0.14)$. Thus, although we observed considerable variation among females,

247 and those with high WW scores sometimes produced large oocytes, the more wing-worn females

248 tended to have smaller oocytes than would be predicted from their body sizes.

250 Pollen counts

251 Of the 2000 pollen grains identified, 100 from each of 10 females from 22 June and 10 from 3 August,

252 all but one was from alfalfa. That single grain appeared to be from a plant of the family Asteraceae.

253 After identifying the 100 grains from each female, we scanned the whole sample on each slide and 254 found no other non-alfalfa pollen.

\section{DISCUSSION}

\section{Seasonal trends in wing wear}


258 We documented a steady decline in wing condition over the first 3-4 weeks of each nesting season at

259 both sites, with some females having wings tattered along their entire distal margins by the second or

260 third week following bee release. Many late-season females had deep excisions in their wings. Based

261 on mark-recapture observations of individual bees, wing wear of bumble bees (Foster \& Cartar, 2011)

262 and honey bees (Higginson \& Barnard, 2004) accelerates with age. The lack of an accelerating, or

263 even a steadily increasing, seasonal trend in wing wear for M. rotundata in our data could have several

264 causes. First, unlike the studies of the social bees, we did not score WW on the same bees each week.

265 If M. rotundata females with extremely worn wings die late in the season, as occurs in bumble bees

266 (see below), they would be absent from our samples. Second, there may be an inherent non-linear

267 relationship between age and wing wear, in which females progress through the first three (i.e., lowest)

268 WW classes quickly, but then more slowly through the remaining WW classes, perhaps because the

269 open wing margin is now closer to supporting wing veins. Third, the appearance of an overlapping

270 second generation of females with less wing wear late in the season would result in smaller mean WW

271 values if females of both generations are mixed in samples. Based on the reappearance of females with

272 low WW values late in the season, second generation females did not show up in the MT samples until

273 the seventh (2012) or eighth week (2011) following the initial release of the bees. Based both on WW

274 values and the appearance of emergence holes in nests, they appeared at the UT site earlier, perhaps by

275 weeks four and five. The great variability of wing wear in M. rotundata, even prior to emergence of a

276 second generation, suggests that it is a weak predictor of mean calendar age, as is the case for the

277 solitary bees Anthidium manicatum (L.) (Mueller \& Wolf-Mueller, 1993), Dieunomia triangulifera

278 (Vachal) (Wuellner, 1999), and Euglossa spp. (López-Uribe, Oi \& Del Lama, 2008).

Rapid accumulation of wing wear in $M$. rotundata is expected from the high level of flight

280 activity of nesting females. Klostermeyer \& Gerber (1969) estimated that completion of a single nest

281 cell involved an average of 15 leaf-collecting trips and 17 pollen- and nectar-foraging trips, and later 
282 estimated that females typically provision 12-16 cells during their lives (Gerber \& Klostermeyer, 283 1972). Szabo \& Smith (1972) reported that females visited an average of 7.5 flowers per foraging trip 284 at air temperatures of $17-21^{\circ} \mathrm{C}$, and 17.8 per trip at $21-25^{\circ} \mathrm{C}$. Based on these combined estimates, 285 females would make 384-512 total trips during their adult lives, depending on cell number and 286 temperature, visiting thousands of flowers in the process. This may be an underestimate, because some 287 females are known to provision $>25$ cells in a lifetime (T. Pitts-Singer, unpublished data). The values 288 for the variables leading to these estimates are certainly time- and site-specific, but they illustrate the 289 amount of time females spend foraging. To this, we can add the unknown number of visits to flowers 290 to collect nectar and pollen for self-maintenance. Although females probably forage near nests when

291 flowers are available during the peak of alfalfa bloom, M. rotundata females sometimes forage 292 hundreds of meters from nests (Tepedino, 1983; St. Amand, Skinner \& Peaden, 2000). Finally, it is 293 also possible that females sustain wing wear when 1) fighting with nest-intruding females over 294 possession of tunnels, 2) colliding with other bees in crowded commercial bee shelters, 3) interacting 295 with males during attempted matings, and 4) moving about in the confines of nest tunnels, which are 296 often barely wider than their bodies (K.M. O'Neill et al., 2010). Insight into the potential causes and consequences of wing wear in M. rotundata is gained from 298 studies of other bees. In worker bumble bees, variation in wing area lost was related not to flight 299 frequency or time spent in flight, but to collisions of wings with vegetation during foraging (Foster \& 300 Cartar, 2011). Greater degrees of wing wear increased mortality rates (Cartar, 1992) and influenced 301 the choice of flower patches visited (Foster \& Cartar, 2010), but had no effect on pollen load sizes, the 302 duration of foraging trips (Cartar, 1992), or the energetic cost of flight (Hedenström, Ellington \& Wolf, 303 2001). Rodd, Plowright \& Owen (1980) suggest that the rapid increase in mortality rates of Bombus 304 workers after two weeks of adult life is due to accumulated wing damage that hinders their ability to 305 escape predators. In honey bees (Apis mellifera L.), workers with greater wing wear tended to accept 
306 smaller, lower-quality inflorescences, leading to reduced foraging efficiency (Higginson \& Barnard, 307 2004). Similarly, an experimentally-induced reduction in wing area significantly decreases the rate of

308 food delivery and increases mortality of worker honey bees (Dukas \& Dukas, 2011). Overall, this brief

309 review suggests that wing wear in M. rotundata might also be linked to foraging success, with

310 consequences for the sustainability of nesting performance as the summer progresses. More direct

311 experimental tests of this hypothesis are required, but such tests also need to take into account the

312 possibility that declining performance of wing-worn females late in the season is also related to the

313 smaller body lipid reserves and floral resource availability. In addition, there is also the question of

314 whether the fitness consequences of declining flight performance related to wing wear are similar in

315 social and solitary bees. In eusocial bees, older, physically-worn workers are replaced by younger bees

316 as the season progresses, but there is no such compensating mechanism for solitary bees. One study of

317 a solitary bee Ceratina calcarata showed that females with greater wing wear produced smaller

318 clutches and smaller overall masses of adult offspring, and that wing wear appeared to be the primary

319 correlate of declining levels of parental investment across the nesting season (Rehan \& Richards, 320 2010).

\section{Seasonal trends in lipid content}

323 In a previous study of adults active in the field in 2006 and 2007 at the same MT site in this study,

324 female M. rotundata reared under controlled laboratory conditions from early fall to early summer 325 emerged with a mean proportion body lipids of $15-18 \%$ (K.M. O'Neill et al., 2011). In the present

326 study, the fact that the initial mean values for $\mathrm{P}_{\mathrm{L}}$ of newly-emerged field-collected females were just 7-

$32711 \%$ could be related to several differences between the studies. First, yearly differences in floral

328 resource quality and quantity could affect the lipid content of the bees at the time they entered diapause

329 the previous year. Second, there might be differences in stored-lipid metabolism between bees reared 
330 under tightly-controlled laboratory conditions (K.M. O'Neill et al., 2011) and those experiencing

331 variable on-farm rearing conditions (present study). In our earlier study, variation in temperature

332 during pre-release rearing explained $13-27 \%$ of the variance in the proportion of body lipids of newly-

333 emerged adults, with the optimal rearing temperatures for maintaining maximum lipid reserves being

$33427-29^{\circ} \mathrm{C}$. In addition, brief exposure of bees to $38^{\circ} \mathrm{C}$ during the last week of adult rearing in the lab

335 causes significant lipid loss. In the field, bees could regularly experience such spikes in temperature

336 when cells are placed into field shelters at the time of release. In late June or early July, when females

337 complete pupal-adult development, it would not be unusual for shelter temperatures to exceed optimal

338 temperatures for lipid conservation. Finally, bees reared in the laboratory were frozen for lipid analysis

339 within several minutes to several hours of their emergence as adults (K.M. O'Neill et al., 2011). In the

340 present study, however, they were likely to be at least 1-2 days old when collected; some may have

341 been older than that because, even in controlled laboratory conditions, females reared at the same

342 temperature do not all emerge on the same day (K.M. O'Neill et al., 2011). Thus, during the brief

343 interval between emergence and collection, females in the present study may have already converted a

344 considerable portion of their fat-body lipids to proteins destined for egg production (Sihag, 1985,

345 1986). In the halictid bee Lasioglossum malachurum, a species that overwinters as adults, depletion of

346 fat reserves during solitary nest-founding is rapid and more lipids are lost during that period than

347 during hibernation (Weissel et al., 2012).

348 Whatever the reason for the initial $\mathrm{P}_{\mathrm{L}}$ values, our results indicate that lipid content in adult

349 females declines rapidly after field release and then stabilizes at a lower level later in the season. Some

350 of the temporal variation we observed after the initial decline is likely due to emergence of a second

351 generation that introduced individuals with greater lipid content into later samples. In the UT samples,

352 the significant mid-season increase in lipid content on 18 July (i.e., JD 200), which was about one

353 month after bee release, corresponded to an influx of newly-emerged females with lower WW values. 
354 Apparently, as these second-generation females aged, mean $\mathrm{P}_{\mathrm{L}}$ values again declined one week later.

355 Examining the trend of $\mathrm{P}_{\mathrm{L}}$ as function of wing wear (as a measure of physiological age) rather than

356 date, removed much of the temporal fluctuation probably because it removed the influence of second-

357 generation females on the trend.

358 Because we extracted lipids in bulk, we do not know what proportion of lipids remaining after

359 the initial decline were present in fat bodies, where they could act as nutrient reserves. Lipids extracted

360 from tissues not involved in lipid storage likely create a baseline value to lipid content below which

361 living females cannot decline, even after most fat body lipids have been depleted. Thus, as with wing

362 wear, females whose lipid levels dropped below a critical level may have disappeared from the

363 population. In addition, an unknown amount of lipids in the samples might have been derived from

364 pollen in the guts of females so its contribution deserves further analysis. Alfalfa pollen, which

365 constituted almost all of what we identified in dissected females, contains about $8.5 \%$ lipids (Roulston

$366 \&$ Cane, 2002). Alfalfa pollen is typically most of what females collect when nesting in commercial

367 alfalfa fields in Montana (K.M. O'Neill et al., 2004; R.P. O'Neill \& K.M. O'Neill, 2010). The volume

368 of pollen in the guts of females is unknown, but the estimated lipid content of an average pollen load at

369 a time when alfalfa is the main source of pollen is just $0.06 \mathrm{~mm}^{3}$ (R.P. O'Neill \& K.M. O'Neill, 2010).

370 Based on qualitative assessment of pollen loads within the gut, however, we found no tendency for

371 females to increase pollen consumption as their lipid content dropped. In fact, pollen consumption

372 may have declined because all females collected on 22 June had crops containing large masses of

373 pollen, whereas after that date most had very little pollen in their crops even when their midguts were

374 full of pollen. Richards (1994) reported that $100 \%$ of M. rotundata females had pollen in their crops,

375 but noted only its presence or absence, so his results are not comparable to ours. We should also re-

376 emphasize that lab-reared females without access to pollen had even higher $\mathrm{P}_{\mathrm{L}}$ values (K.M. O'Neill et

377 al., 2011) than the field-collected females in this study that carried pollen in their guts. 
At present, it seems clear that females used up a considerable proportion of their body lipids

379

380 soon after emergence, and it is reasonable to assume that this resulted mainly from fat body materials being converted to materials used to make oocytes (Sihag, 1985, 1986; Klowden, 2002; Arrese \& Soulages, 2010). A more detailed analysis of the anatomical sources of lipids extracted from females and the types of lipids extracted at different times of the year would be needed to further explore the significance of our results. There is also the question of the significance of the decline in fat body lipids for aspects of female reproductive performance. First, flight metabolism of bees is thought to be fueled by carbohydrates derived from nectar and stored in the crop rather by nutrients mobilized from fat bodies (Suarez et al., 2005). Second, fat body lipids accumulated during larval development are important sources of nutrients for egg production and adult maintenance for insects in general (Pan, Bell \&Telfer, 1969; Keely, 1985; Arrese \& Soulages, 2010). Bees, however, have to consume pollen to initiate oogenesis (see below), so some of the materials for oocyte production may come from the adult diet. Nevertheless, as in Lasioglossum malachurum (Weissel et al., 2012), depletion of lipid levels in $M$. rotundata continues during the early part of the season despite consumption of pollen soon after adult emergence.

\section{Seasonal trends in oocyte size}

In solitary nest-provisioning Hymenoptera, eggs are larger relative to body size than they are in related parasitoid and social species, and each female lays relatively few eggs in her lifetime (Iwata, 1955, 1960; Iwata \& Sakagami, 1966; K.M. O'Neill, 2001; Rozen, 2003). Such large eggs require substantial investment from females. Our data indicate that oocyte size varied with both female size (K.M. O'Neill, Delphia \& R.P. O’Neill, 2014) and collection date (present study). These results are consistent with several of Richards' (1994) conclusions concerning seasonal trends in oocyte development in $M$. rotundata. First, females in his samples did not fully mature oocytes until the second week after eclosion; one of us (T. Pitts-Singer, unpublished data), nevertheless, has observed females ovipositing 
402 just two days after emergence. Megachile rotundata females lay eggs only when a cell is fully 403 provisioned, so newly-emerged females can make progress towards constructing and provisioning their

404 first nest cells before they are capable of laying eggs. Second, although we were unable to collect

405 females beyond $\sim 6$ weeks past adult emergence, oocyte size showed evidence of a decline by 3 August.

406 The pollen masses seen in guts of recently-released females are consistent with experimental

407 evidence that pollen consumption is a prerequisite for oocyte development. Richards (1994) showed

408 that female M. rotundata fed honey, but lacking access to pollen, failed to initiate vitellogenesis. In

409 fact, the broad taxonomic occurrence of a link between pollen consumption by newly-emerged adult

410 female bees and their schedule of egg development suggests that it is an evolutionarily-ancient trait in

411 apiform Apoidea. Adult consumption of pollen is known to be necessary for the initiation of

412 vitellogenesis and oocyte development in bees of the families Apidae (Human et. al., 2007), Halictidae

413 (Bell, 1973; Wuellner, 1999), and Megachilidae (Sihag 1986; Richards, 1994); bees of these three

414 families are estimated to have diverged from one another 90-100 million years ago during the

415 Cretaceous (Brady, Larkin \& Danforth, 2009). Sihag (1986) also demonstrated that the inclusion of

416 protein, rather than just carbohydrates, in an artificial diet was required for vitellogenesis in three

417 species of south Asian Megachile managed for alfalfa pollination. Females of two of the species,

418 which were multivoltine (Sihag, 1983), exhibited their highest rates of oocyte development when they

419 emerged at the time of year when alfalfa flowers were most abundant (Sihag, 1986). At that time, the

420 average delay between adult female emergence and first oviposition was slightly longer than four days

421 in both species. On a natural diet of alfalfa pollen and nectar, vitellogenesis commenced in the second

422 day following emergence and the first oocytes to develop chorions appeared on day four. In Megachile

423 flavipes Spinola, vitellogenins that eventually provide proteins for eggs appear in hemolymph on the

424 second day after emergence (Sihag, 1985). 
Older M. rotundata females apparently reach an age when they begin to produce smaller

426

427

428

429

430

431

432

433

434 Bienefeld, 2009).

\section{Conclusions}

436 Even when nesting in commercial alfalfa fields with high floral densities, $M$. rotundata females face 437 seasonally-dynamic environments. First, higher field temperatures result in greater prevalence of a 438 condition referred to as "pollen ball", that is cells in which the pollen masses are not consumed and in 439 which no bee offspring develop (Pitts-Singer \& James, 2008). Second, the prevalences of chalkbrood 440 disease and pteromalid wasp parasitism change seasonally (R.P. O’Neill, 2004). Third, floral resource

441 quality and quantity declines as alfalfa senesces (Strickler \& Freitas, 1999; see also Kim \& Thorp, 442 2001; Pitts-Singer, 2013a), with the result that pollen types used change seasonally (R.P. O’Neill \& 443 K.M. O’Neill, 2010). Lower resource levels for caged females in experimental studies resulted in 444 smaller offspring size and fewer offspring per female (Peterson \& Roitberg, 2006). Seasonal declines 445 in investment per offspring have also been documented for the megachilid bee Osmia lignaria (Torchio $446 \&$ Tepedino, 1980), though not for the megachilid Hoplitis anthocopoides (Schenk) (Strickler, 1982). 447 Fourth, in nest shelters provided for M. rotundata, the number of available nest tunnels may decline 
448 later in the summer and higher ratios of females to available nest sites have been associated with lower 449 offspring production (Mayer, 1994; but see Pitts-Singer, 2013a).

450 The results of this and other studies (Richards, 1994) make it clear that, besides the

451 environmental factors discussed above, seasonal changes in the condition of the females themselves

452 might also affect the temporal consistency of reproductive performance. Females experience a steady

453 increase in wing wear that could affect their flight efficiency and resource choices. Soon after

454 emergence, they face a rapid drop in lipid stores that can be ameliorated only by feeding on pollen, and 455 any pollen collected for personal consumption cannot be used for nest provisioning. Lastly, relative 456 oocyte size starts to decline within six weeks of emergence, continues through the remainder of the 457 summer (Richards, 1994), and is perhaps related to declining lipid reserves.

458 During management of M. rotundata for pollination services (Pitts-Singer \& Cane, 2011), not

459 all factors that affect female reproductive success can be controlled (e.g. weather, wing wear).

460 However, certain management practices have the potential to impact adult female reproductive

461 performance in ways related to our findings. First, because females vary considerably in the amount of

462 lipids they carry into adult life and then rapidly deplete these reserves upon emergence, it is important

463 to rear bees at temperatures that enhance conservation of lipid reserves sequestered during larval

464 development (Pitts-Singer \& James, 2009; K.M. O'Neill et al., 2011). Second, because females require

465 a source of pollen following emergence, in order to stimulate oogenesis and supplement nutrients no

466 longer supplied by fat body reserves, care must be taken to release females at a time when sufficient

467 bloom is present to support female pollen requirements (as has also been recommended by Richards,

468 1994). The date of commencement of alfalfa bloom is influenced by the vagaries of weather.

469 However, manipulation of pre-release rearing temperatures can be used to slow bee development if

470 bloom is delayed (Yocum et al., 2010), not only to ensure adequate pollen resources for females, but to

471 enhance levels of pollination (Bosch \& Kemp, 2005). Nevetheless, although seasonal changes in 
472 condition have been documented, the degree to which these changes affect physiological performance 473 and fitness remains to be fully explored. 


\section{ACKNOWLEDGEMENTS}

476 We thank William Kemp and Ruth O’Neill for comments on the manuscript, Ellen Klomps for

477 assistance in field studies, and John and Shelley Wold and Mike Spackman for allowing access to the

478 farms on which the bees were collected.

\section{ADDITIONAL INFORMATION AND DECLARATIONS}

481 Funding

482 Funding for the research was supplied by the Montana Agricultural Experiment Station,

483 the Montana Alfalfa Seed Growers Association, the Montana Department of Agriculture,

484 the Western Alfalfa Seed Growers Association. The funders had no role in study design, data collection and

485 analysis, decision to publish, or preparation of the manuscript.

487 Grant Disclosures

488 The following grant information was disclosed by the authors:

489 Montana Agricultural Experiment Station

490 Montana Alfalfa Seed Growers Association

491 Montana Department of Agriculture

492 Western Alfalfa Seed Growers Association

495 Competing Interests

496 The authors declare that they have no competing interests. 

performed the research, analyzed the data, wrote the paper, prepared figures and tables, and reviewed drafts of the paper. 


\section{REFERENCES}

505 Al-Lawati H, Bienefeld K. 2009. Maternal age effects on embryo mortality and juvenile development of offspring in the honey bee (Hymenoptera: Apidae). Annals of the Entomological Society of America 102: 881-888.

508 509 of Entomology 55: 207-225.

Bell WJ. 1973. Factors controlling initiation of vitellogenesis in a primitively social bee Lasioglossum zephyrum (Hymenoptera: Halictidae). Insectes Sociaux 20: 253-260.

Bosch J, Kemp WP. 2005. Alfalfa leafcutting bee population dynamics, flower availability, and pollination rates in two Oregon alfalfa fields. Journal of Economic Entomology 98: 1077-1086.

Brady SG, Larkin L, Danforth, BN. 2009. Bees, ants, and stinging wasps (Aculeata) In: Hedges SB, Kumar S, eds. The Timetree of Life. New York: Oxford University Press, 264-269.

Buckner JS, Kemp WP, Bosch J. 2004. Characterization of triacylglycerols from overwintering prepupae of the alfalfa pollinator Megachile rotundata (Hymenoptera: Megachilidae). Archives of Insect Biochemistry and Physiology 57: 1-14.

Cartar RV. 1992. Morphological senescence and longevity: an experiment relating wing wear and life span in foraging wild bees. Journal of Animal Ecology 61: 225-231.

Dukas R, Dukas L. 2011. Coping with non-repairable body damage: the effects of wing damage on foraging performance in bees. Animal Behaviour 81: 635-638.

Foster DJ, Cartar RV. 2010. Wing wear affects wing use and choice of floral density in foraging bumble bees. Behavioral Ecology 22: 52-59.

Foster DJ, Cartar RV. 2011. What causes wing wear in foraging bumble bees? Journal of Experimental Biology 214: 1896-1901. 
527 Gerber HS, Klostermeyer EC. 1972. Factors affecting the sex ratio and nesting behavior of the

Hedenström A, Ellington CP, Wolf TJ. 2001. Wing wear, aerodynamics and flight energetics in alfalfa leafcutting bee. Washington Experiment Station Technical Bulletin 73, Pullman: bumblebees (Bombus terrestris): an experimental study. Functional Ecology 15: 417-422.

Higginson AD, Barnard CJ. 2004. Accumulating wing damage affects foraging decisions in honeybees (Apis mellifera L.). Ecological Entomology 29: 52-59.

Human H, Nicolson SW, Strauss K, Pirk CWW, Dietemann V. 2007. Influence of pollen quality on ovarian development in honeybee workers (Apis mellifera scutellata). Journal of Insect Physiology 53: 649-655.

Iwata K. 1955. The comparative anatomy of the ovary in Hymenoptera. Part I. Aculeata. Mushi 29: 17-34.

Iwata K. 1960. The comparative anatomy of the ovary in Hymenoptera. Supplement on Aculeata with descriptions of ovarian eggs of certain species. Acta Hymenopterologica 1: 91-97.

Iwata K, Sakagami SF. 1966. Gigantism and dwarfism in bee eggs in relation to modes of life, with notes on the number of ovarioles. Japanese Journal of Ecology 16: 4-16.

Keely LL. 1985. Physiology and biochemistry of the fat body. In: Kerkut GA, Gilbert LI, eds. Comprehensive insect physiology, biochemistry and pharmacology volume 3. Oxford, U.K.: Pergamon Press, 211-248.

Kim J, Thorp RW. 2001. Maternal investment and size number trade-off in a bee, Megachile apicalis, in seasonal environments. Oecologia 126: 451-456.

Klostermeyer EC, Gerber HS. 1969. Nesting behavior of Megachile rotundata (Hymenoptera: Megachilidae) monitored with an event recorder. Annals of the Entomological Society of America 62: 1321-1325. 
551 Klowden M. 2002. Physiological systems in insects. Academic Press, New York, NY.

552 López-Uribe MM, Oi CA, Del Lama MA. 2008. Nectar-foraging behavior of Euglossine bees

(Hymenoptera: Apidae) in urban areas. Apidologie 39: 410-418.

554 Mayer DF. 1994. Effects of male to female ratio and number of females per nesting tunnel on sex ratio and number of progeny of the alfalfa leafcutter bee Megachile rotundata (Hymenoptera: Megachilidae). Journal of the Entomological Society of British Columbia 91: 43-46.

Mueller UG, Wolf-Mueller B. 1993. A method for estimating the age of bees: age-dependent wing wear and coloration in the wool-carder bee Anthidium manicatum (Hymenoptera: Megachilidae). Journal of Insect Behavior 6: 529-537.

O’Neill KM. 2001. Solitary wasps: behavior and natural history. Ithaca NY: Cornell University Press.

O’Neill KM, Pearce AM. 2007. Ovary structure and oocyte size in relation to female size and age in the brood parasitic wasp Stizoides renicinctus (Say) (Hymenoptera: Crabronidae). Proceedings of the Entomological Society of Washington 109: 836-840.

O'Neill KM, Delphia CM, O'Neill RP. 2014. Oocyte size, egg index, and body lipid content in relation to body size in the solitary bee Megachile rotundata. PeerJ 2:e314; DOI 10.7717/peerj.314.

O’Neill KM, O’Neill RP, Blodgett S, Fultz JE. 2004. Variation in Megachile rotundata pollen load composition in relation to flower diversity (Hymenoptera: Megachilidae). Journal of the Kansas Entomological Society 77: 619-625.

O'Neill KM, O'Neill RP, Kemp WP, Delphia CM. 2011. Effect of temperature on post-wintering development and total lipid content of alfalfa leafcutting bees. Environmental Entomology 40: 917-930. 
O'Neill KM, Pearce AM, O'Neill RP, Miller RS. 2010. Offspring size and sex ratio variation in a feral population of alfalfa leafcutting bees (Hymenoptera: Megachilidae). Annals of the Entomological Society of America 103: 775-784.

O'Neill RP. 2004. Seasonal and spatial patterns of mortality and sex ratio in the alfalfa leafcutting bee, Megachile rotundata (F.). M.S. Thesis, Montana State University.

O’Neill RP, O'Neill KM. 2010. Pollen load composition and size in the leafcutting bee Megachile rotundata (Hymenoptera: Megachilidae). Apidologie 42: 223-233.

Pan ML, Bell WJ, Telfer WH. 1969. Vitellogenic blood protein synthesis by insect fat body. Science 165: 393-394.

Peterson J H, Roitberg BD. 2006. Impact of resources levels on sex ratio and resource allocation in the solitary bee, Megachile rotundata. Environmental Entomology 35: 1404-1410.

Pitts-Singer TL. 2013a. Intended release and actual retention of alfalfa leafcutting bees (Hymenoptera: Megachilidae) for pollination in commercial alfalfa seed fields. Journal of Economic Entomology 106: 576-586.

Pitts-Singer TL. 2013b. Variation in alfalfa leafcutting bee, Megachile rotundata, reproductive success according to location of nests in U.S. commercial domiciles. Journal of Economic Entomology 106: 543-551.

Pitts-Singer TL, Cane JH. 2011. The alfalfa leafcutting bee, Megachile rotundata: the world's most intensively managed solitary bee. Annual Review of Entomology 56: 221-237.

Pitts-Singer TL, James RR. 2005. Emergence success and sex ratio of commercial alfalfa leafcutting bees from the United States and Canada. Journal of Economic Entomology 98: 1785- 1790.

Pitts-Singer TL, James RR. 2008. Do weather conditions correlate with findings in failed, provision-filled cells of Megachile rotundata (Hymenoptera: Megachilidae) in western North America. Journal of Economic Entomology 101: 674-685. 
598 Pitts-Singer TL, James RR. 2009. Prewinter management affects Megachile rotundata (Hymenoptera: Megachilidae) prepupal physiology and adult emergence and survival. Journal of Economic Entomology 102: 1407-1416.

601 Rehan S, Richards MH. 2010. The influence of maternal quality on brood sex allocation in the small carpenter bee, Ceratina calcarata. Ethology 116: 876-887.

603 Richards KW. 1994. Ovarian development in the alfalfa leafcutter bee, Megachile rotundata. Journal of Apicultural Research 33: 199-203.

605 Richards MH, Packer. L 1994. Trophic aspects of caste determination in Halictus ligatus, a 606 primitively eusocial sweat bee. Behavioral Ecology and Sociobiology 34: 385-391.

607

608

609

610

Richards KW, Whitfield GH, Schaalje GB. 1987. Effects of temperature and duration of winter storage on survival and period of emergence for the alfalfa leafcutter bee (Hymenoptera: Megachilidae). Journal of the Kansas Entomology Society 60: 70-76.

Rodd FH, Plowright RC, Owen RE. 1980. Mortality rates of adult bumble bee workers (Hymenoptera: Apidae). Canadian Journal of Zoology 58: 1718-1721.

Rozen JG. 2003. Eggs, ovarioles numbers, and modes of parasitism of cleptoparasitic bees, with emphasis on neotropical species (Hymenoptera: Apoidea). American Museum Novitates 3413: $1-36$.

Roulston TH, Cane JH. 2002. Pollen nutritional content and digestibility for animals. Plant Systematics and Evolution 222: 617-643.

Sihag RC. 1983. Life cycle pattern, seasonal mortality, problem of parasitization and sex ratio pattern in alfalfa pollinating megachilid bees. Zeitschrift für angewandte Entomologie 96: 368-379.

Sihag RC. 1985. Vitellogenin of alfalfa pollinating bee Megachile flavipes. Current Science 54: 9294. 
621 Sihag RC. 1986. Reproduction in alfalfa pollinating sub-tropical megachilid bees. 4. Vitellogenesis and oosorption, and factors inducing these processes. Zoologischer Anzeiger 216: 231-249.

623 St. Amand PC, Skinner DZ, Peaden RN. 2000. Risk of alfalfa transgene dissemination and scaledependent effects. Theoretical and Applied Genetics 101: 107-114. Evolution 36: 1098-1100.

Strickler K, Freitas S. 1999. Interactions between floral resources and bee (Hymenoptera: Megachilidae) in commercial alfalfa seed fields. Environmental Entomology 28: 178-187.

Strohm E. 2000. Factors affecting the body size and fat content in a digger wasp. Oecologia 123: 184-191.

Suarez RK, Darveau CA, Welch KC, O’Brien DM, Roubik DW, Hochachka PW. 2005. Energy metabolism in orchid bee flight muscles: carbohydrate fuels all. Journal of Experimental Biology 208: 3573-3579. Research 11: 157-165.

Tepedino VJ. 1983. An open-field test of Megachile rotundata as a potential pollinator in hybrid carrot seed fields. Journal of Apicultural Research 22: 64-68.

639 Torchio P, Tepedino VJ. 1980. Sex ratio, body size, and seasonality in a solitary bee, Osmia lignaria propinqua Cresson (Hymenoptera: Megachilidae). Evolution 34: 993-1003.

641 Weissel N, Mitesser O, Poethke HJ, Strohm E. 2012. Availability and depletion of fat reserves in halictid foundress queens with a focus on solitary nest founding. Insectes Sociaux 59: 67-74. 
645 Yocum GD, Rhinehart JP, West M, Kemp WP. 2010. Interrupted incubation and short-term

646 storage of the alfalfa pollinator Megachile rotundata (Hymenoptera: Megachilidae): a potential

647 tool for synchronizing bees with bloom. Journal of Economic Entomology 103: 234-241.

648 Zar JH. 1999. Biostatistical Analysis (4th edition). Prentice Hall, Englewood Cliffs, NJ. 
1

Seasonal changes in the index of wing wear (WW).

Light blue circles represent raw data, dark blue circles and solid lines represent the mean values for each date. Means associated with different letters are significantly different at $P<$ 0.05 (Dunn's Test). Total sample sizes for each date were $N=50$ (MT 2011) and $N=30$ (MT 2012 and UT 2012). 

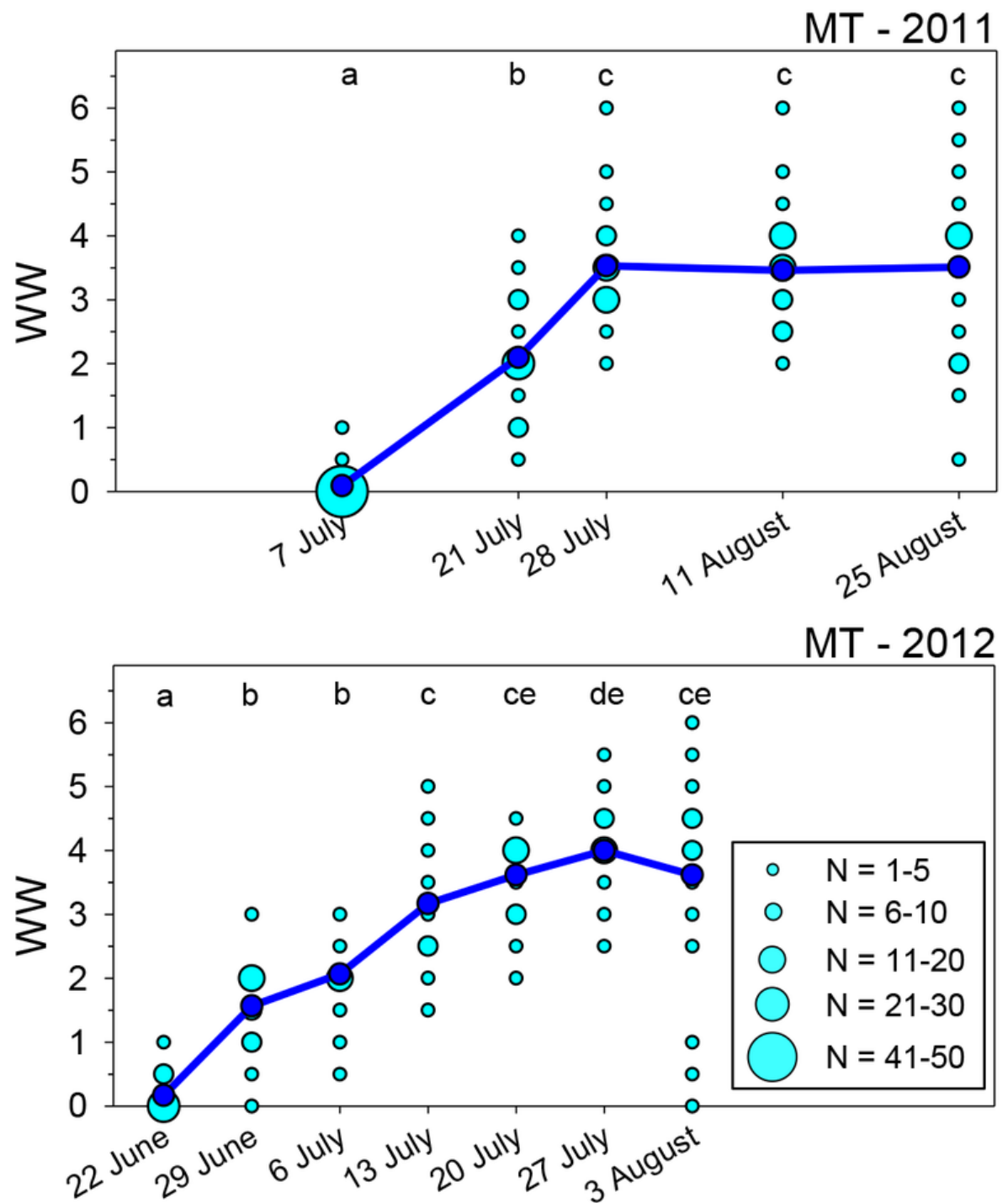

UT - 2012

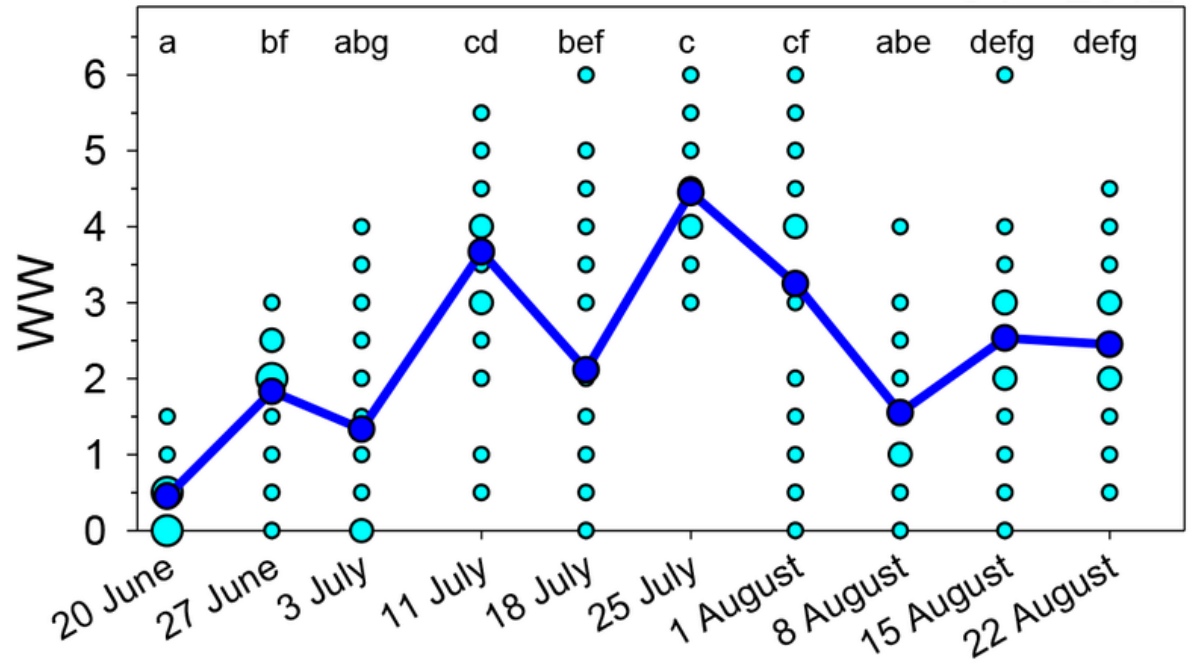

Date of collection 
2

Seasonal changes in the relationship of $P_{\mathrm{L}}$ for female $M$. rotundata to date of collection (left; red lines) and WW (right; blue lines).

Means associated with different letters are significantly different at $P<0.05$ (SNK Test). 

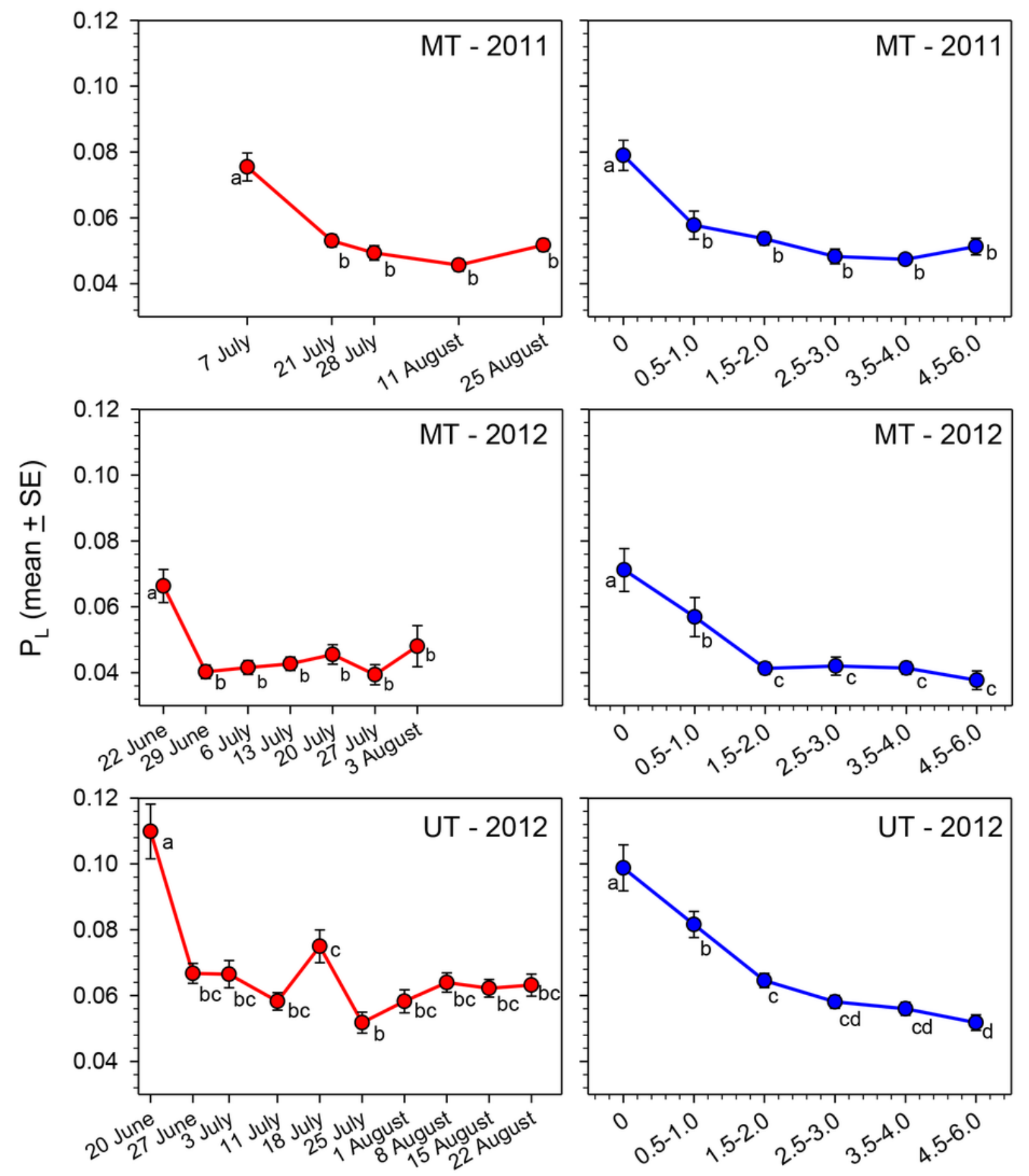

Date

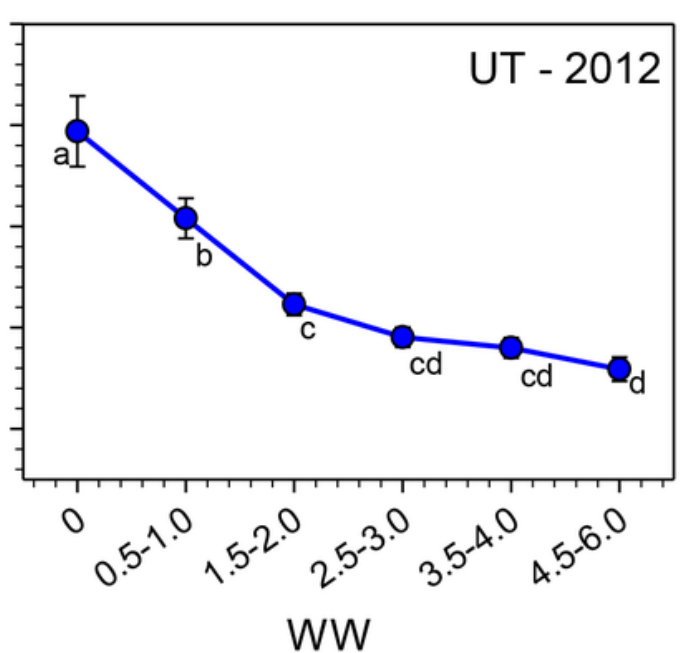


3

Seasonal changes in body size-adjusted oocyte size variables by sampling date for bees collected in MT in 2012.

Means associated with different letters are significantly different at $P<0.05$ (Dunn's Test).

Samples sizes for each date were $N=30$ for 22 June, $N=26$ for 29 June, $N=32$ for 6 July, $N$ $=27$ for 20 July, and $N=30$ for 3 August.
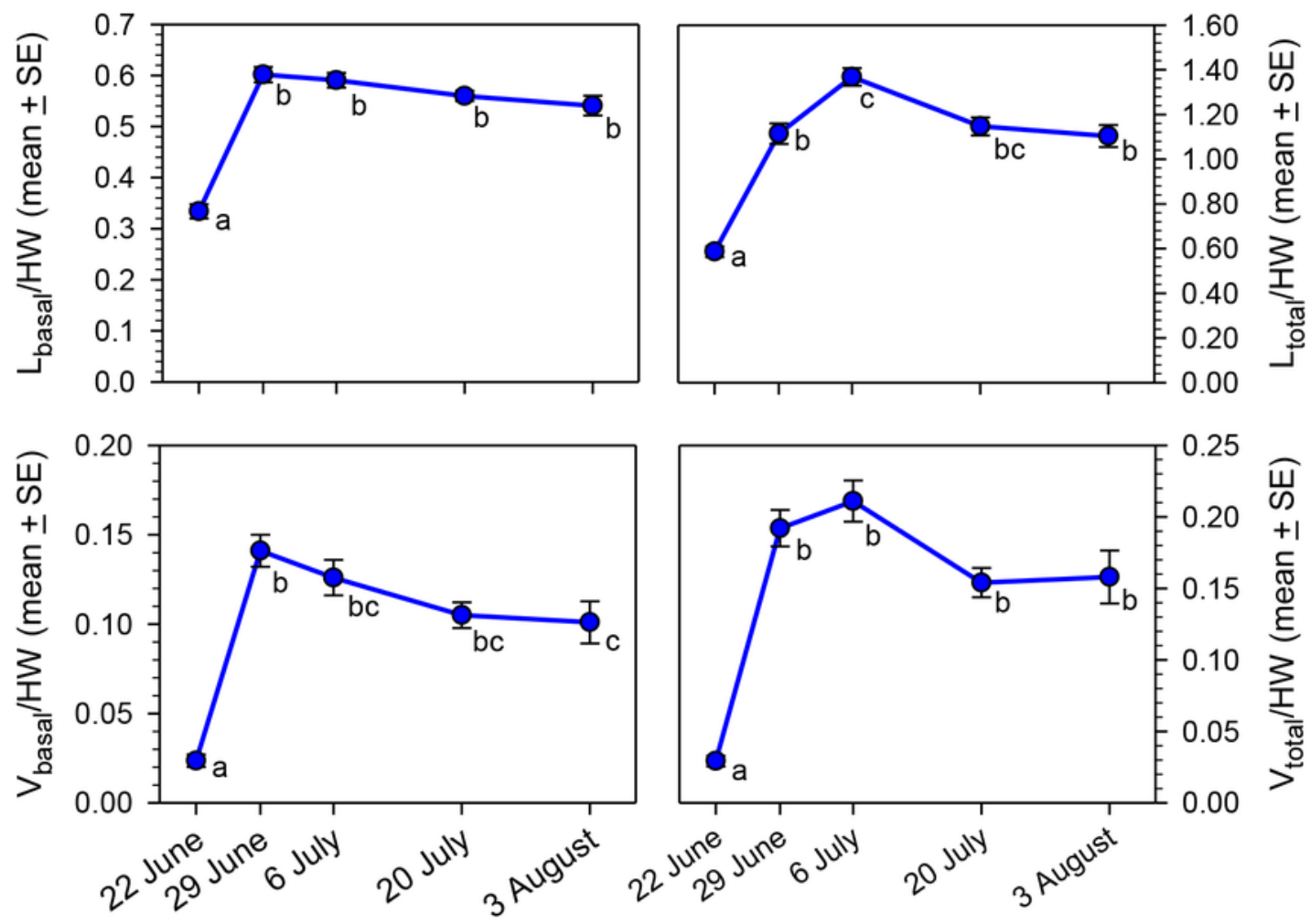

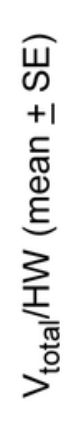


Proportions of females in different wing wear index (WW) categories with either negative or positive residuals for the regressions of $\mathrm{L}_{\text {basal, }} \mathrm{L}_{\text {total, }}, \mathrm{V}_{\text {basal, }}$ and $\mathrm{V}_{\text {total }}$ (all transformed as the square root of the val

Females with negative residuals had smaller than expected oocyte sizes based on the HWoocyte size linear regression equation. The regression equations for oocyte variable (squareroot transformed) on HW were: 1) $L_{\text {basal }}=0.329+(0.341)(\mathrm{HW}) ; F=81.6, \mathrm{df}=1,111, P<$ $\left.0.001,2) \mathrm{L}_{\text {total }}=0.0981+(0.615)(\mathrm{HW}) ; F=48.1, \mathrm{df}=1,111, P<0.001 ; 3\right) \mathrm{V}_{\text {basal }}=0.0422+$ (0.279) $(\mathrm{HW}) ; F=56.4, \mathrm{df}=1,111, P<0.001$, and 4) $\mathrm{V}_{\text {total }}=-0.0167+(0.374)(\mathrm{HW}) ; F=56.4$, $\mathrm{df}=1,111, P<0.001$. Mean $\pm \mathrm{SE}$ WW values are superimposed above the bars (sample sizes for means range from 52 to 61 ).

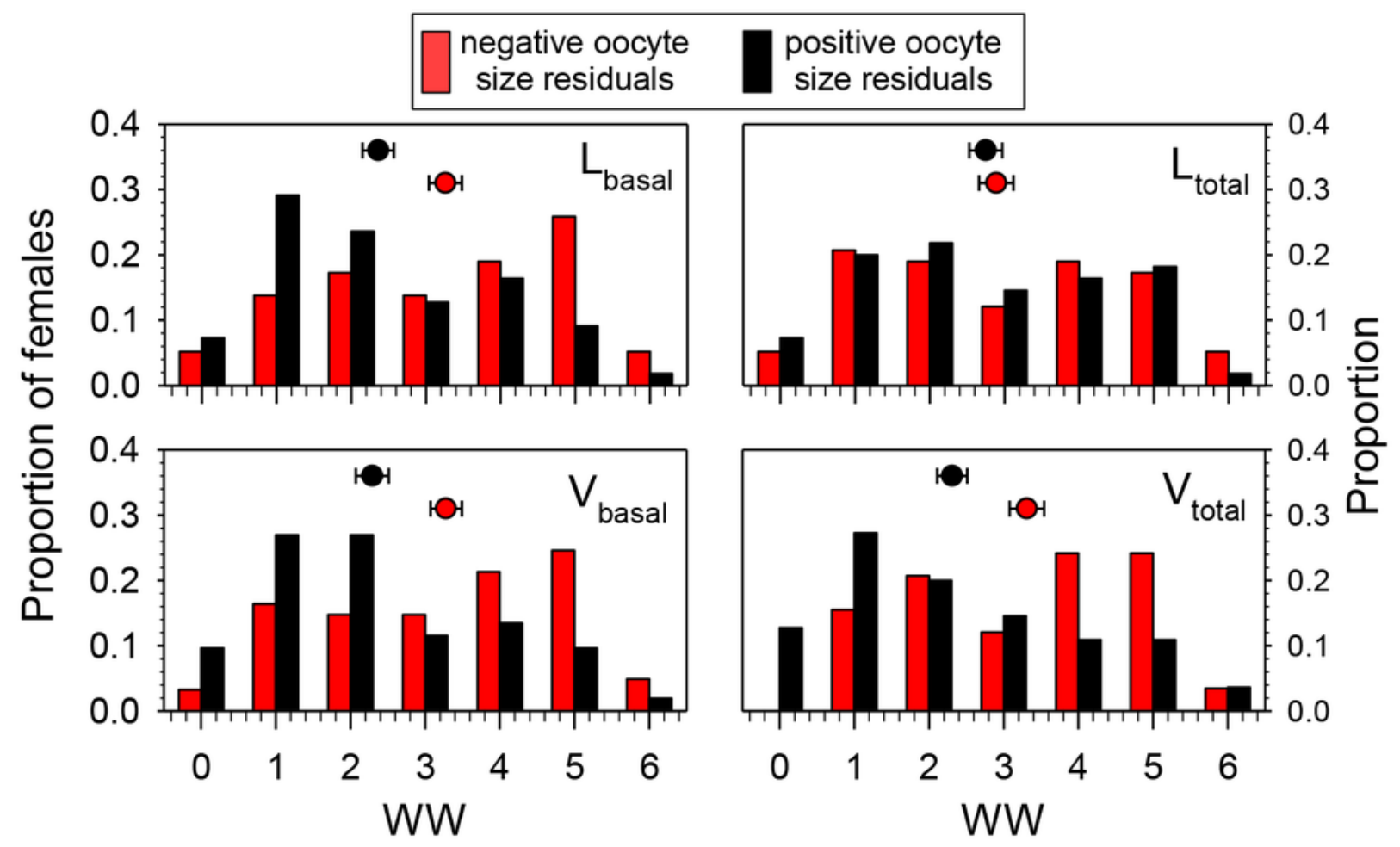




\section{Table $\mathbf{1}$ (on next page)}

One-way analyses of variance for the relationship of $P_{L}$ to date of collection and WW for M. rotundata females. All analyses were done with arcsine-transformed $P_{\mathrm{L}}$ values. 


\begin{tabular}{|c|c|c|c|c|c|c|}
\hline Site & Year & $\boldsymbol{F}$ & d.f. & Probability & \multicolumn{2}{|c|}{ Percent decline in mean $P_{L}$ from: } \\
\hline \multicolumn{5}{|c|}{$P_{L}$ as function of date* } & $\begin{array}{l}\text { First to second } \\
\text { collection date }\end{array}$ & $\begin{array}{l}\text { First to final } \\
\text { collection date }\end{array}$ \\
\hline \multirow[t]{2}{*}{ MT } & 2011 & 17.80 & 4,245 & $P<0.001$ & $29.7 \%$ & $31.5 \%$ \\
\hline & 2012 & 5.58 & 6,203 & $P<0.001$ & $39.2 \%$ & $27.5 \%$ \\
\hline UT & 2012 & 12.81 & 9,290 & $P<0.001$ & $39.2 \%$ & $42.5 \%$ \\
\hline \multicolumn{5}{|c|}{$P_{L}$ as function of $\mathbf{W} W^{*}$} & $\begin{array}{c}W W=0 \text { to } \\
W W=0.5-1.0\end{array}$ & $\begin{array}{c}W W=0 \text { to } \\
W W=4.5-6.0\end{array}$ \\
\hline \multirow[t]{2}{*}{ MT } & 2011 & 17.31 & 5,244 & $P<0.001$ & $26.8 \%$ & $35.1 \%$ \\
\hline & 2012 & 10.53 & 5,204 & $P<0.001$ & $20.1 \%$ & $47.5 \%$ \\
\hline UT & 2012 & 24.33 & 5,294 & $P<0.001$ & $17.4 \%$ & $47.5 \%$ \\
\hline
\end{tabular}

3 * All analyses were done with arcsine-transformed $\mathrm{P}_{\mathrm{L}}$ values. 
Table 2 (on next page)

Proportions of females with $P_{L}$ values $\geq 0.10$ and $\leq 0.05$, comparing the first collection date each year with all other collection dates combined. 
Table 2. Proportions of females with $P_{L}$ values $\geq 0.10$ and $\leq \mathbf{0 . 0 5}$, comparing the first collection date each year with all other collection dates combined.

\begin{tabular}{|c|c|c|c|c|c|c|c|}
\hline \multirow[b]{2}{*}{ Site } & \multirow[b]{2}{*}{ Year } & \multicolumn{2}{|c|}{$\begin{array}{l}\text { Proportion females } \\
\text { with } P_{L} \geq 0.10\end{array}$} & \multirow{2}{*}{$\begin{array}{c}\text { Fisher } \\
\text { Exact } \\
\text { Test } \\
\text { Probability }\end{array}$} & \multicolumn{2}{|c|}{$\begin{array}{c}\text { Proportion females } \\
\text { with } P_{L} \leq 0.05\end{array}$} & \multirow{2}{*}{$\begin{array}{c}\text { Fisher } \\
\text { Exact } \\
\text { Test } \\
\text { Probability }\end{array}$} \\
\hline & & $\begin{array}{c}\text { First } \\
\text { collection } \\
\text { date }\end{array}$ & $\begin{array}{l}\text { All other } \\
\text { collection } \\
\text { dates }\end{array}$ & & $\begin{array}{c}\text { First } \\
\text { collection } \\
\text { date }\end{array}$ & $\begin{array}{c}\text { All other } \\
\text { collection } \\
\text { dates }\end{array}$ & \\
\hline \multirow[t]{2}{*}{ MT } & 2011 & 0.260 & 0.005 & $P<0.001$ & 0.300 & 0.525 & $P<0.01$ \\
\hline & 2012 & 0.166 & 0.011 & $P<0.001$ & 0.233 & 0.761 & $P<0.001$ \\
\hline UT & 2012 & 0.566 & 0.048 & $P<0.001$ & 0.033 & 0.265 & $P<0.001$ \\
\hline
\end{tabular}

